\title{
Induced Abortion Procedure
}

National Cancer Institute

\section{Source}

National Cancer Institute. Induced Abortion Procedure. NCI Thesaurus. Code C92954.

A surgical or medical procedure that terminates a pregnancy by removing the products of conception. 